\title{
Assessment of the behavior of vertical ties in RC structures under progressive collapse
}

\author{
Didier Droogné | Wouter Botte | Robby Caspeele
}

Department of Structural Engineering, Ghent University, Ghent, Belgium

Correspondence

Didier Droogné, MSc., Department of Structural Engineering, Ghent University, TechnologieparkZwijnaarde 60, 9052 Ghent, Belgium.

Email:didier.droogne@ugent.be

\begin{abstract}
Despite the recent amount of theoretical and technological developments, structural robustness is still an issue of controversy being underlined by several progressive collapses in the past. Current design codes point out different strategies, among which strategies to limit progressive structural damage by applying prescriptive design and detailing rules. For example, for consequence class 2 structures, EN1991-1-7 defines a risk class CC2b for which also vertical ties are required. However, the background of the design values of vertical ties in current codes is not clear and their adequacy should be validated. Moreover, effects such as membrane action and Vierendeel action are important to consider when assessing structural robustness and are difficult to incorporate when applying only traditional design methodologies. To this extent, a set of numerical simulations have been executed in this contribution in order to verify and investigate the progressive collapse behavior of $\mathrm{RC}$ frames including the redistribution of internal forces and the response of the vertical ties in columns.
\end{abstract}

\section{KEYWORDS}

Prescriptive tie forces, reinforced concrete frames, structural robustness

\section{1 | INTRODUCTION}

In recent years, progressive collapse has drawn significant attention in the engineering community because of its potential to cause disproportional damage and casualties being underlined by structural failures in the past involving severe consequences. The increasing interest resulted in several experimental test programs, the development of various specific simulation techniques to model progressive collapse, and the implementation of design guidelines in standards.

The first code provisions for structural robustness were introduced in the United Kingdom with the implementation of the Fifth Amendment of the Building Regulations [1]. The basic idea of these first code provisions was that minimum levels of structural robustness must be ensured to allow buildings to redistribute the loads and maintain their structural stability after the loss of one or more structural components. This basic idea is still present in most current international design codes, which are often an evolution of the guidelines introduced in the Fifth Amendment. An overview in time of the development of structural design codes for structural robustness can be found in several studies [2-4]. A frequently found strategy in current codes is the application of prescriptive design and detailing rules. These prescriptive design and detailing rules should enhance the development of alternate load paths to redistribute the loads when a load-bearing member collapses and hence limit the damage and consequences of accidental situations.

For example, for consequence class 2 structures, EN1991-1-7 defines a risk class $\mathrm{CC} 2 \mathrm{~b}$ for which, next to horizontal ties, also the design of vertical ties is required [5]. However, the background of the design values to be adopted for the design of these vertical ties is not clear and their adequacy should be validated considering current state-of-the-art research. Moreover, effects due to membrane action and Vierendeel action, which can be activated by the large deformations occurring in case of the notional removal of supporting elements, are important to consider when assessing structural robustness. Note that due to the large deformations, the effects by membrane action and Vierendeel action are difficult to incorporate when applying only traditional design methodologies and hence require specialized knowledge. The effects of membrane action on the progressive collapse resistance of reinforced concrete ( $R C$ ) elements have been investigated extensively, both experimentally [6-8] and numerically $[9,10]$. Research on

(C) 2019 Ernst \& Sohn Verlag für Architektur und technische Wissenschaften GmbH \& Co. KG, Berlin. 
Vierendeel action in case of progressive collapse, on the other hand, is limited. In experimental tests on RC structures [11-13], Vierendeel action was clearly observed and found to be an important resisting effect against progressive collapse.

In this contribution, a set of numerical simulations has been executed in order to verify the progressive collapse behavior of RC frames in case of notional column removal scenarios, focusing on the response of the vertical ties in the columns and the internal force redistribution of the RC frame. Based on the outcomes of the numerical analyses, the requirements for vertical ties in EN1991-1-7 are evaluated.

\section{2 | PRESCRIPTIVE TYING RULES}

Applying prescriptive tying rules is one of the most commonly used techniques for progressive collapse resistance design since quantitative guidelines associated with such an approach can be easily adopted in standards. The latter also allows for an easier implementation and application by practicing engineers, compared to other methods that require more specialized knowledge of the designers. Nevertheless, current available prescriptive tie rules are not adequate for every case and very often the fundamental principles or background information justifying the proposed prescriptive rules is missing. For instance, inadequacies and proposals for improvement of the tie force method found in the British Standards are given by Yi [14].

According to EN1991-1-7 [5], for buildings in class CC2b, horizontal ties should be provided together with vertical ties in all supporting columns and walls. Or alternatively the building should be checked to ensure that upon the removal of each supporting column and each beam supporting a column or any nominal section of load-bearing walls, the building remains stable and that any local damage does not exceed a certain limit. The recommended limit of admissible local failure in case of a notional load-bearing element removal is $15 \%$ of the floor area or $100 \mathrm{~m}^{2}$, whichever is smaller, in each of two adjacent stories. Next, to design the vertical ties, EN1991-1-7 states the following [5]:

"In the case of framed buildings (e.g. steel or reinforced concrete structures) the columns and walls carrying vertical actions should be capable of resisting an accidental design tensile force equal to the largest design vertical permanent and variable load reaction applied to the column from any one story. Such accidental design loading should not be assumed to act simultaneously with permanent and variable actions that may be acting on the structure."

However, the interpretation of such a statement is difficult, as it is unclear which reaction force should be considered to design the vertical ties of the columns. Hence, in this contribution, it is first investigated what happens to the axial column forces when a column is notionally removed from a general exemplary RC frame at ground floor. The notional removal of a column is chosen as this method provides an objective way to introduce some local damage in the structure and to check the structural integrity of the structure in case of some arbitrary local damage.

\section{3 | NUMERICAL MODEL}

In this contribution, the numerical analyses were performed using the open-source software OpenSees [15]. This software was originally developed to model the behavior of structures under seismic actions and recently it has been applied in several studies to investigate progressive collapse as well $[10,16]$. The main modeling and material assumptions and the experimental validation of the developed model are discussed by Droogné et al. [17]. To model the notional removal of a column, the following load steps were implemented:

- First, the intact frame is subjected to the gravity loads, a superimposed dead load (SDL) acting on all beams and a live load (LL), which only acts on the beams situated in the directly affected part (DAP) above the removed column (Figure 1 shows the situation considered in relation to the removal of column 4). After applying the aforementioned loads, the internal forces are determined at the top end of the column, which will be notionally removed.

- Second, the numerical model is reset (i.e., all external loads, strains, and stresses are removed) and the considered column is deleted in the model. Once the column is deleted, the gravity loads, SDLs and LLs, are applied stepwise on the damaged frame and simultaneously the internal forces and bending moments, as determined at the end of step 1, are stepwise applied as external forces on the damaged frame. By applying this procedure, the deformations, stresses, and strains found in the RC frame at the end of this second step are the same as at the end of step 1.

- In a third load step, the notional removal of the column is modeled by gradually decreasing the externally applied forces and bending moments. Note that depending on the strength of the RC frame, it is possible that the frame already fails before the external forces applied in phase 2 are completely taken away. In the other case, the $\mathrm{RC}$ frame remains stable after a notional column removal.

- Furthermore, note that a static analysis was used, hence dynamic effects are not modeled nor taken into account by dynamic incremental factors.

\section{4 | CASE STUDIES}

To investigate the behavior of a RC frame subjected to a notional column removal, an internal frame of a general office building designed according to the Eurocodes was selected [18]. Further details of this frame, such as the reinforcement scheme of the beams and columns and the applied loads (i.e., an SDL and LL), can be found in the study by Droogné et al. [17,18] and in Figure 1.

In this contribution, four different notional column removal scenarios at ground floor are considered, that is, removal of column 4 (symmetric scenario), 5, 6, and 7 (asymmetric scenarios). 


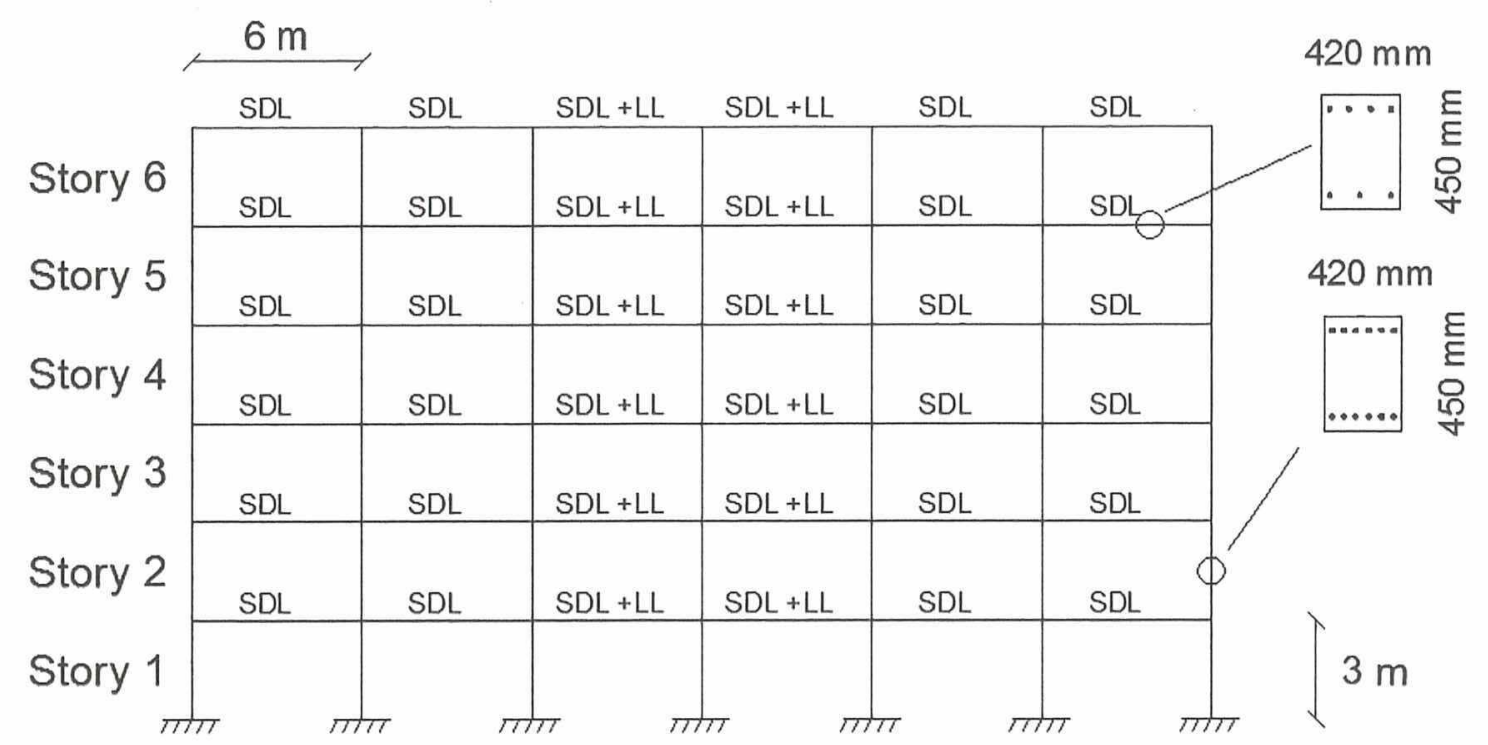

Col. 1 Col. 2 Col. 3 Col. 4 Col. 5 Col. 6 Col. 7

$\begin{array}{ll}\text { SDL: } 37.5 \mathrm{kN} / \mathrm{m} & \text { Beams: } 4 \varnothing 25 \text { (top) }+3 \varnothing 20 \text { (bottom) } \\ \text { LL: } 18 \mathrm{kN} / \mathrm{m} & \text { Columns: } 6 \varnothing 18 \text { (top) }+6 \varnothing 18 \text { (bottom) }\end{array}$

FIGURE 1 Overview of considered RC frame

\section{5 | RESULTS}

In the current literature, basic insights into the different mechanisms involved in the load transfer of RC frames subjected to a column removal are not available. Therefore, different analysis types were performed in this contribution. The first analysis considered the frame described in section 4 in which the beams and columns were modeled by linear elastic elements and without the consideration of secondorder effects and axial deformations of the columns. In the second analysis, the elements were modeled with linear elastic elements, now including axial deformations of the columns. By executing an analysis without and with consideration of axial deformations, the importance of the deviating deformations of the different elements on the load redistribution is quantified. Next in the third analysis, both geometrical and material nonlinearities were included to enable a more accurate prediction.

\section{1 | Observations for DAP}

As the main interest is the design of the vertical ties, particular attention is given to the normal force distribution in the columns above and next to the removed column. Note that irrespective of the adopted modeling approach, the same axial forces are found in the columns for the undamaged frame as in this undamaged situation the frame still behaves linear elastically and is not subjected to significant nonlinear effects and large axial deformations. However, once the lower column is removed, the axial load distribution in the columns changes. In case the analysis is performed without considering axial deformations of the elements and taking into account that all beams

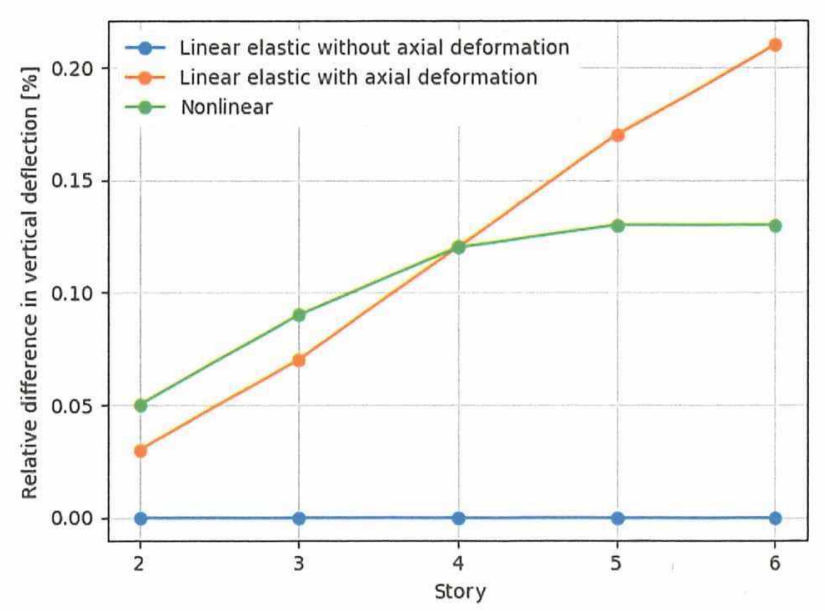

FIGURE 2 Relative difference between vertical deflections of the different columns above the removed column 4

have the same bending stiffness and are loaded by the same uniform load, each story has the same vertical deflection for all damage scenarios (Figure 2). Figure 2 shows the relative difference between the vertical deflection at the top of the removed column ( $v_{\text {removed column }}$ ) and the vertical deflection at the top of the column at the ith story ( $v_{\text {column story, }}$ ) according to Equation 1 in case column 4 is removed. Consequently when neglecting the axial deformations of the columns in the analysis, no normal forces are developed in the columns of the DAP.

$$
\text { Rel.diff. }=\left(\frac{v_{\text {column storey }, \mathrm{i}}-v_{\text {removed column }}}{v_{\text {removed column }}}\right) \times 100
$$



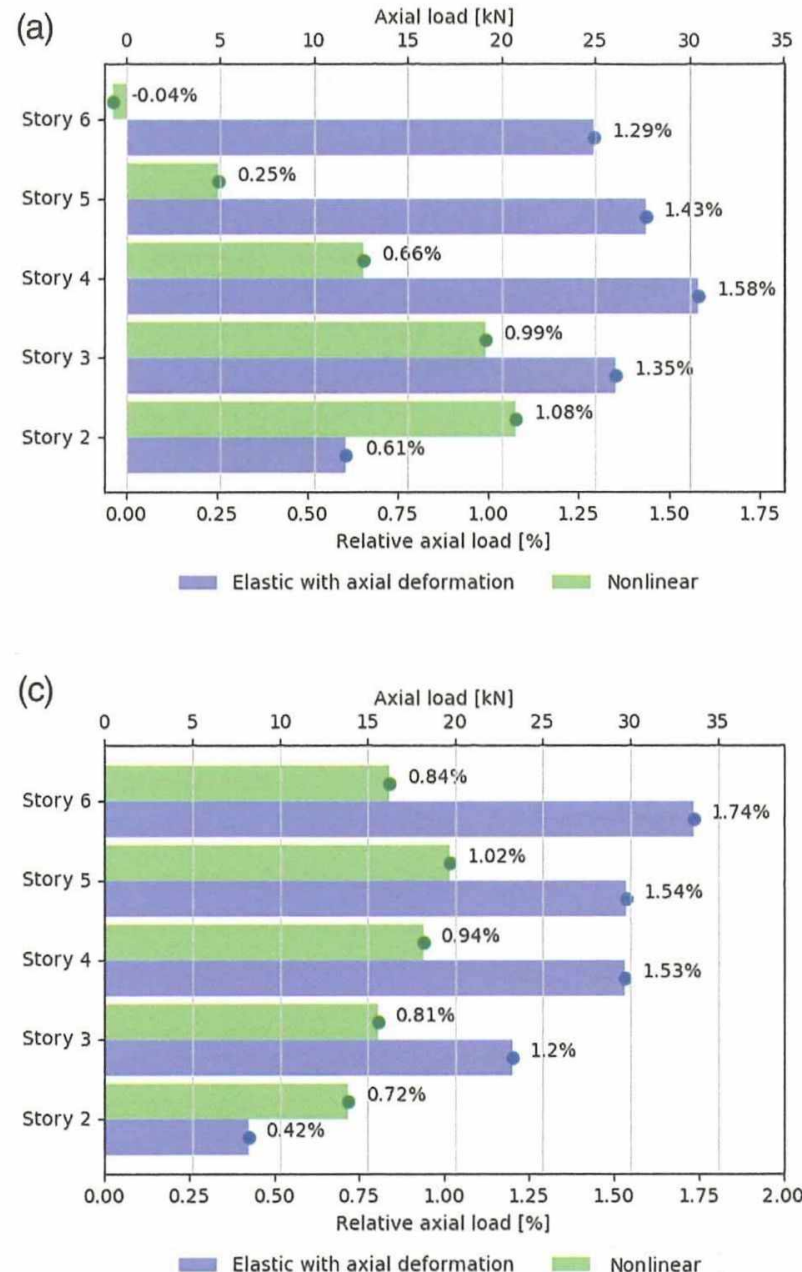
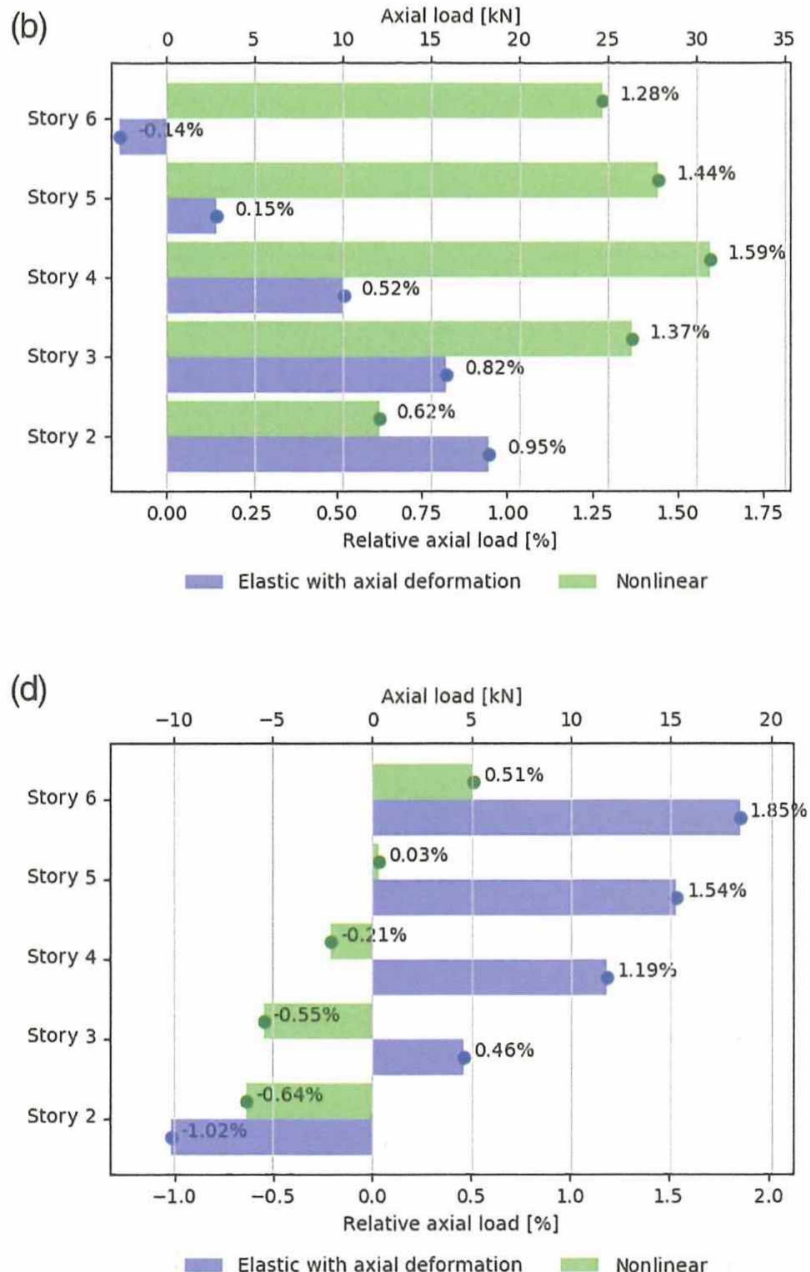

FIGURE 3 Distribution of the axial loads of the columns above the respective removed column: (a) column 4, (b) column 5, (c) column 6, and (d) column 7

TABLE 1 Maximum vertical deflection after column removal

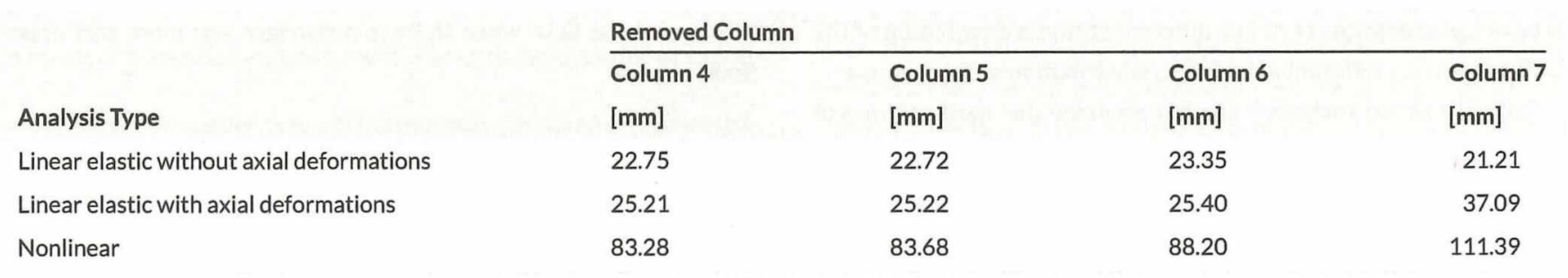

Applying a linear elastic analysis and considering axial deformations, the vertical deflections increase almost linearly for higher stories and axial forces are found in the columns above the respective removed column. The axial load distributions are illustrated in Figure 3 for all considered damage scenarios (both with absolute values and relative values in percentages to the normal force acting on the removed column before column removal) in case the axial deformations of the columns are taken into account. Due to the different axial deformations (Figure 2) of the columns, new deformation states and equilibria have to be found to redistribute all the loads over all stories. For the nonlinear analysis, the increase in deflections for higher stories is not linear anymore (Figure 2) and different axial load distributions are obtained (Figure 3a) due to other effects such as geometrical and material nonlinearities and the development of plastic hinges. In case column 7 is removed, the vertical deflections even decrease for higher stories that results in the development of tensile forces in the columns of the DAP (Figure 3d). Note that for the nonlinear analyses also much larger vertical deflections are found after the notional column removal (Table 1).

Comparing the different column removal scenarios of columns 4-6, it is clear that reducing the frame to a set of symmetrical beams with a set of springs with equal spring stiffness as boundary conditions will deviate from reality for the removal of columns 5 and 6 . Removing column 5 or 6 leads to an unsymmetrical situation that has consequences with respect to the load redistribution (Figure $3 b$ and $c$ ). Furthermore, based on the performed analysis one can conclude that assuming the 
(a)

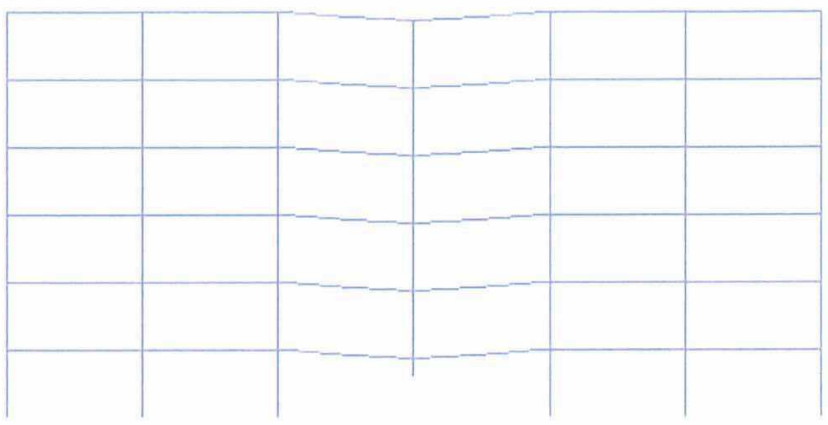

(b)

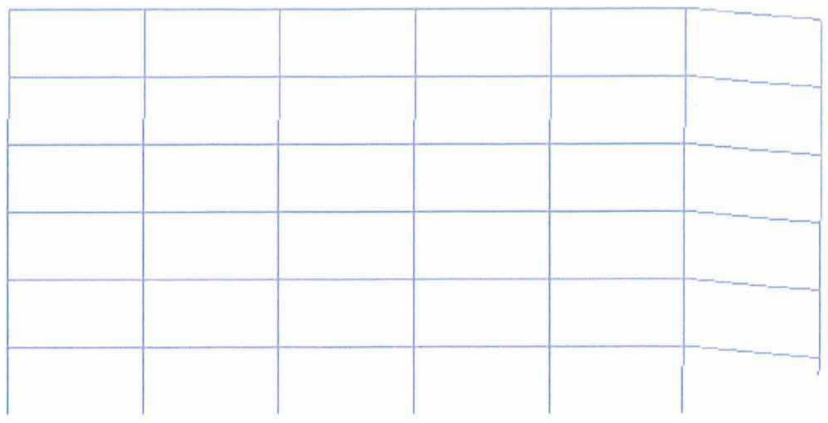

FIGURE 4 Deformed frame after notional column removal of column 4 (a) and column 7 (b)

(a)

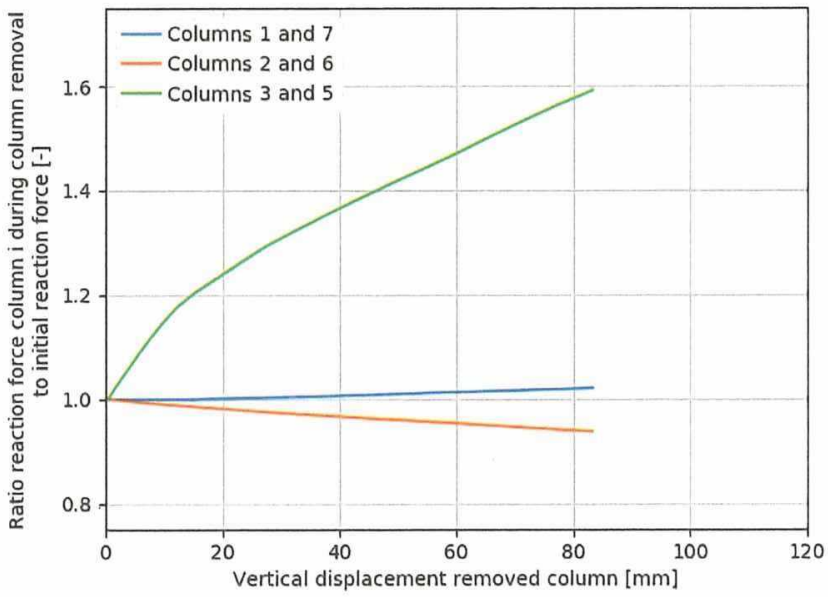

(b)

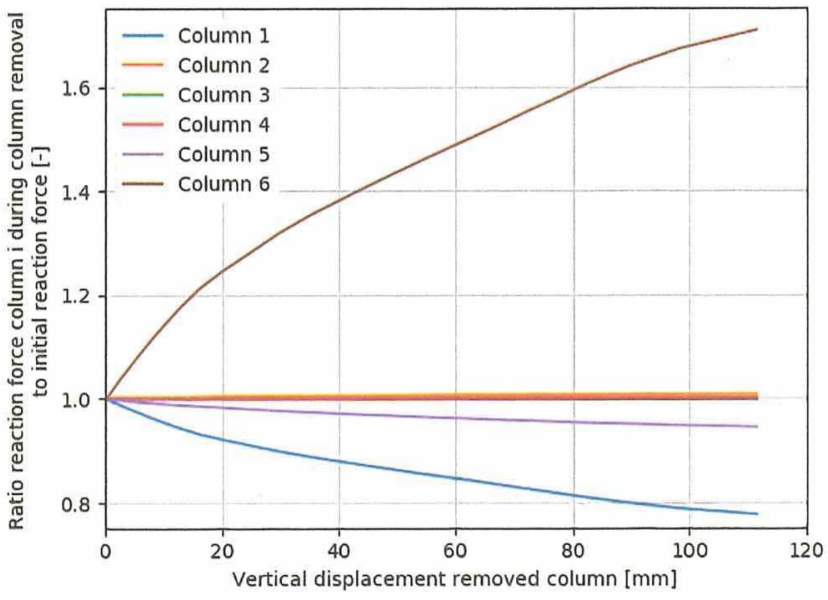

FIGURE 5 Evolution of the reaction forces at ground floor for the respective damage scenario: (a) removal column 4 and (b) removal column 7

same vertical deflection at mid-span for each story of the DAP as done by Izzudin et al. [20] also deviates from reality and does not correspond to the real force redistribution after column removal. The different damage scenarios result in a different stiffness distribution of the DAP and hence a different axial-force redistribution in the columns.

From the above analyses it can be concluded that most columns of the DAP are mainly subjected to compressive forces even when a column is notionally removed. Only in case an edge column is removed all beams of the DAP will act as a cantilever and tension forces can be found in the lower columns (Figure $3 d$ ) due to the development of a "Vierendeel" mechanism. The development of a "Vierendeel mechanism is illustrated in Figure 4 in case of the notional removal of columns 4 and 7 . As a consequence, the addition of vertical ties within the columns to improve the resistance against progressive collapse seems only to be effective for the removal of an edge column. Still the maximum tension force is, however, much smaller in absolute value than the original acting compressive force on the removed column (i.e., 0.64\%) and can be resisted by the reinforcement present in the column. For the other damage scenarios, the compressive forces are also much smaller after column removal than before column removal and hence nondecisive for the design. Note, however, that local tensile forces may occur in case dynamic effects are taken into account. Nevertheless, in a full-scale experiment by Sasani et al. [11], in which a column of a real building was dynamically removed, only small tensile forces were observed in the upper columns during the dynamic phase and in the final steady state only compressive forces appeared in the columns. As shown by Droogné et al. [17], vertical ties will be effective only to suspend the DAP when there is a stronger and more stiff upper floor.

\section{2 | Observations for IAP}

To get a better insight into the different mechanisms which are involved in the load redistribution of RC frames subjected to a column removal, also the behavior of the IAP is discussed. In the following, the results for the IAP are discussed in case a nonlinear analysis is applied. In Figure 5, the ratio of the vertical reaction forces during the notional removal of columns 4 and 7 to the initial vertical reaction forces is shown for the column positions at ground floor neighboring the removed column. As can be seen, the supports closest to the removed column show the largest increase in vertical reaction force, whereas the vertical reaction forces of the other supports stay approximately equal or decrease. For the damage scenarios with a column removal of column 5 or 6 , similar conclusions can be made.

Furthermore, from the analyses, it is also observed that the columns just next to the removed column are subjected to significant bending moments, which are much larger compared to the undamaged situations for all considered damage scenarios (Figure 6). Nevertheless, 
(a)

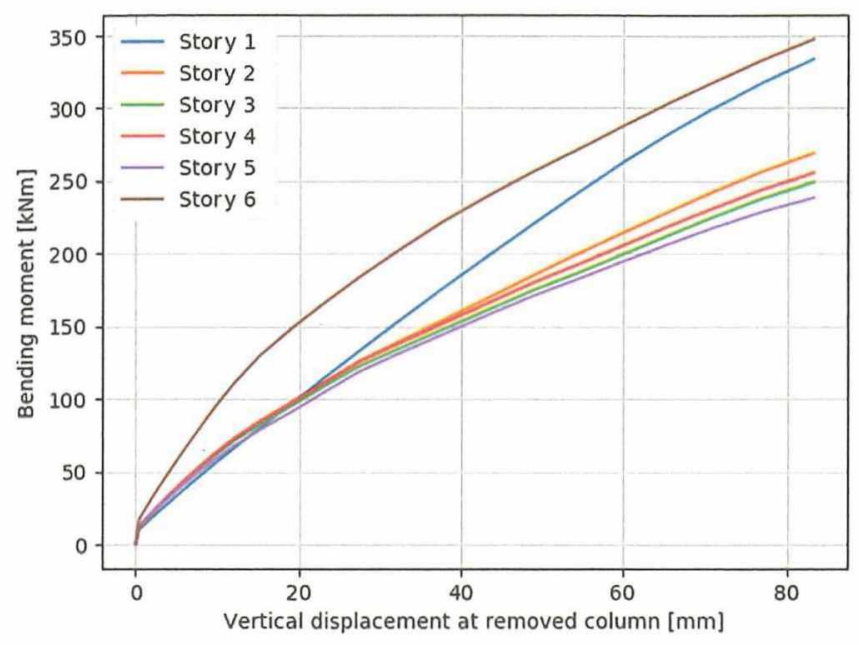

(b)

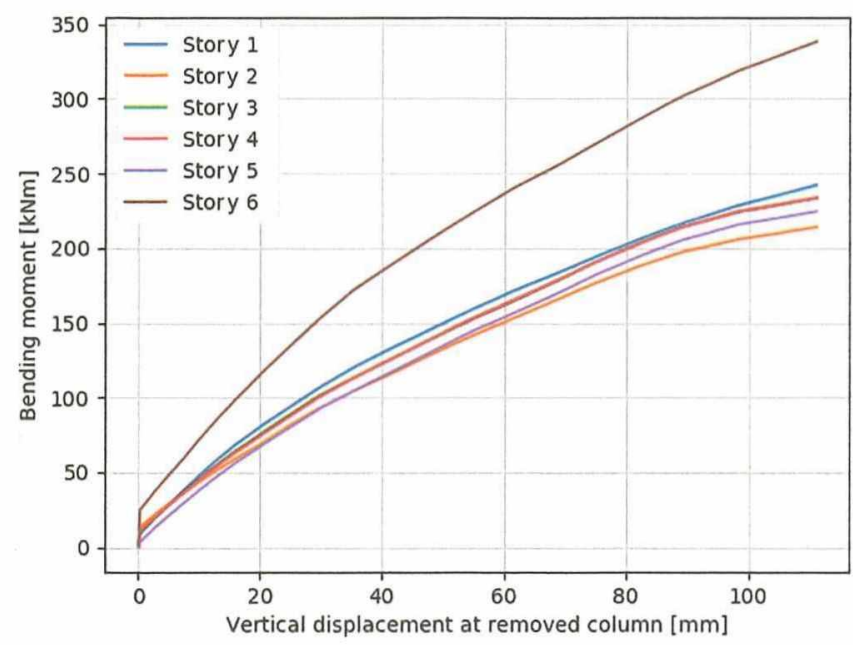

FIGURE 6 Evolution of the maximum bending moments (in absolute values) in the columns immediately next to the DAP for the respective damage scenario: (a) removal column 4 and (b) removal column 7

for the case considered the bending moments capacity of the columns immediately next to the DAP is sufficient to cope with these increased bending moments. It is important to point out that when evaluating the resistance against progressive collapse of a RC frame under a notional column removal, particular attention should be given to the strength of the neighboring columns of the DAP.

Furthermore, next to the axial loads and bending moments acting on the columns, the membrane forces developed in the beams of the DAP should also be taken into account when assessing the progressive collapse resistance of an RC frame $[9,17,19]$.

\section{6 | DISCUSSION}

In relation to previous analyses, the following remarks should be made:

- The numerical model does not include possible 3D effects or contributions of slabs in redistributing the acting loads.

- Dynamic effects that may be involved with the notional column removal are not taken into account.

- Previous results are based on a case-specific study for which no failure occurred for the considered notional column removal scenarios. Hence, the results should be treated as indicative only, as other load redistribution patterns might develop in case of a local failure of elements in either the DAP or IAP.

- The current analyses have been focused on the vertical ties in the DAP. However, from the analyses it is clear that particular attention should be given to the design of the neighboring columns in the accidental situation.

- Further parameter studies should be performed to investigate the influence of the relative stiffness of the elements on the internal force redistribution to assess how additional tie reinforcement could improve the resistance against progressive collapse.

\section{7 | CONCLUSIONS AND RECOMMENDATIONS}

The implementation of prescriptive tie rules is in current practice a common method to design for robustness. However, the background of these rules found in current design guidelines and the actual behavior of RC frames subjected to a notional column removal, which represent a local damage scenario, are often not clear. From the analyses in this contribution, it is observed that the relative deformations - and hence relative stiffness - of the distinct elements have a great influence on the final deformations and internal force redistribution of the frame. Due to the importance of the relative deformations of the distinct elements on the load redistribution, simplifying the analysis of the complete frame to the analysis of a single beam deviates provides results that can significantly deviate from the real behavior. For the considered frame in which all beams have the same design and are loaded by the same loads, no significant tensile or compressive forces are observed in the columns above the internal removed column. In case an edge column is removed, the beams of the DAP will act as cantilever beams and a "Vierendeel" mechanism is developed, which results in some limited tensile forces in the columns of the DAP. Hence based on these observations, placing additional vertical ties will not be effective to increase the resistance against progressive collapse. Only in case if there is a stiff upper structure, vertical ties can be used to suspend the lower located stories in case of a notional column removal. Further, when looking to the columns neighboring the removed column at ground floor, one should take into account a significant increase in the axial load in combination with a large bending moment due to the deflection of the beams in the DAP and the development of "Vierendeel" mechanisms. In order to design against progressive collapse, it is therefore not only necessary that the beams of the DAP can transfer the loads to the IAP but also the columns neighboring the DAP should be capable to resist a combination of large axial loads and bending moments. Finally, it is recommended to develop different prescriptive 
design rules for internal columns and for edge columns as a different behavior and internal force redistribution is observed when a RC frame is subjected to these column removal scenarios.

\section{ACKNOWLEDGMENTS}

The authors wish to thank Ghent University for the financial support from the Special Research Fund (BOF) on the research project "Risk and reliability-based evaluation and development of design guidelines for structural robustness measures in constructions taking into account membrane action".

\section{REFERENCES}

1. Minister of Housing and Local Government. The Building Regulations 1970 (Fifth Amendment), 1970.

2. Adam JM, Parisi F, Sagaseta J, Lu X. Research and practice on progressive collapse and robustness of building structures in the 21st century. Eng Struct. 2018;173:122-49.

3. Kai Q, Li B, Tian Y. Recent progress in understanding of load resisting mechanisms for mitigating progressive collapse. ACl. 2016;309: $1-18$.

4. Byfield M, Mudalige W, Morison C, Stoddart E. A review of progressive collapse research and regulations. Proc Inst Civ Eng - Struct Build. 2014;167:447-456.

5. CEN. Eurocode 1 - Actions on Structures - Part 1-7: General Actions Accidental Actions. Brussels, Belgium: CEN; 2006.

6. Gouverneur D, Caspeele R, Taerwe L. Experimental investigation of the load-displacement behaviour under catenary action in a restrained reinforced concrete slab strip. Eng Struct. 2013;49:10071016.

7. Qian K, Li B, Ma J. Load-carrying mechanism to resist progressive collapse of RC buildings. J Struct Eng. 2014;141:104.

8. Lew HS, Bao Y, Sadek F, Main JA, Pujol S, Sozen MA. An experimental and computational study of reinforced concrete assemblies under a column removal scenario. NIST Technical Note 1720, Gaithersburg, MD. 2011.

9. Botte W, Caspeele R, Gouverneur D, Taerwe L. Influence of membrane action on robustness indicators for concrete frames. Proceedings of the 7th International Conference on Bridge Maintenance, Safety, Management and Life Extension, Shanghai (China), 2014, p. 2038-2046.

10. Bao Y, Kunnath SK, El-Tawil S, Lew HS. Macromodel-based simulation of progressive collapse: RC frame structures. J Struct Eng. 2008;134:1079-1091.

11. Sasani M, Kropelnicki J. Progressive collapse analysis of an RC structure. Struct Design of Tall and Spec Build. 2008;17:757-771.

12. YiW-J, He Q-F, Xiao Y, Kunnath SK. Experimental study on progressive collapse-resistant behavior of reinforced concrete frame structures. Aci Struct J. 2008;105:433-439.

13. Yu J, Tan KH. Experimental study on catenary action of RC beamcolumn sub-assemblages. Proceedings of 3rd Fib International Congress - 2010, Shanghai (China), 2010.

14. Li Y, Lu X, Guan H, Ye L. An improved tie force method for progressive collapse resistance design of reinforced concrete frame structures. Eng Struct. 2011:33:2931-2942

15. OpenSEES. Pacific Earthquake Engineering Research Center Univ. of California. 2007. http://opensees.berkeley.edu

16. Fascetti A, Kunnath SK, Nisticò N. Robustness evaluation of RC frame buildings to progressive collapse. Eng Struct. 2015;86:242-249.

17. Droogné D, Botte W, Caspeele R. Assessment of current design guidelines for vertical ties in relation to progressive collapse of RC structures. Proceedings of IABSE Symposium 2019, Guimaraes, Portugal. 2019.

18. CEN. Eurocode 0 - Basis of Structural Design (+AC:2010). Brussels, Belgium: CEN;2015.

19. Droogné D, Botte W, Caspeele R. A multilevel calculation scheme for risk-based robustness quantification of reinforced concrete frames. Eng Struct. 2018;160:56-70.

20. Izzudin BA, Vlassis AG, Elghazouli AY, Nethercot DA Progressive collapse of multi-storey buildings due to sudden column loss - part I: simplified assessment framework. Eng Struct. 2008;30:1308-1318.

How to cite this article: Droogné D, Botte W, Caspeele R. Assessment of the behavior of vertical ties in RC structures under progressive collapse. ce papers. 2019;3:54-60. https:// doi.org/10.1002/cepa.964 